\title{
A new model for the immobilization of the rat hind limb
}

E.L. Coutinho,

A.R.S. Gomes,

C.N. França and

T.F. Salvini
Unidade de Plasticidade Muscular, Laboratório de Neurociências, Departamento de Fisioterapia, Universidade Federal de São Carlos, São Carlos, SP, Brasil

\author{
Correspondence \\ T.F. Salvini \\ Departamento de Fisioterapia \\ UFSCar \\ 13565-905 São Carlos, SP \\ Brasil \\ Fax: +55-16-261-2081 \\ E-mail: tania@power.ufscar.br \\ Presented at the XVII Annual Meeting \\ of the Federação de Sociedades de \\ Biologia Experimental, Salvador, BA, \\ Brazil, August 28-31, 2002. \\ E.L. Coutinho, A.R.S. Gomes and C.N. \\ França are recipients of Master, $\mathrm{PhD}$ \\ and undergraduate fellowships from \\ CAPES, FAPESP and CNPq, respectively. \\ Publication supported by FAPESP.
}

Received April 12, 2002

Accepted August 22, 2002

\begin{abstract}
An alternative device for the immobilization of the hind limb of the rat was developed to study the effects of chronic disuse on the soleus and tibialis anterior muscles, maintained for 3 weeks in the shortening and the stretching positions, respectively. The proposed device is made of steel mesh and cotton materials, and has some advantages when compared to cast or plaster cast: it is cheaper, lighter $(12 \mathrm{~g}$ or $4 \%$ of the body weight of the rat) and the same unit can be easily adjusted and used several times in the same animal or in animals of similar size. Immobilization is also useful to restrain the movements of the hip, knee, and ankle joints. Male rats ( $291 \pm 35 \mathrm{~g}$ and aged $14 \pm 2$ weeks) were used to develop and test the model. The soleus muscle of 18 rats was maintained in a shortened position for 21 consecutive days and lost $19 \pm 7 \%$ of its length $(\mathrm{P}=0.008)$ and $44 \pm 6 \%$ of its weight $(\mathrm{P}=$ $0.002)$ compared to the contralateral intact muscle. No difference $(P=$ 0.67 ) was found in the stretched tibialis anterior of the same hind limb when compared to the contralateral muscle. No ulcer, sore or foot swelling was observed in the animals. Immobilization was effective in producing chronic muscle disuse in the hind limbs of rats and is an acceptable alternative to the traditional methods of immobilization such as cast or plaster cast.
\end{abstract}

Key words

- Muscle immobilization

- Muscle shortening

- Muscle stretching

- Soleus muscle

- Tibialis anterior

- Skeletal muscle

$\ldots \ldots \ldots \ldots \ldots \ldots . . . .$.
The immobilization of the rat hind limb is frequently used to study the adaptation of skeletal muscle to chronic disuse and also to evaluate the effect of the muscle positions (shortened or stretched) during the disuse period.

One of the most widely used methods for the immobilization of animals is the plaster cast (1-7), but it is very expensive to be frequently used in studies, especially in countries which import it.

The cast is also a popular and inexpensive alternative for the immobilization. Our tests showed that the immobilization made of cast is too heavy, corresponding to about $40-60 \%$ of the body weight of the rat. In addition, this procedure was effective only when the hip joint was immobilized too. Other kinds of difficulties were also found, i.e., some animals showed skin ulceration probably due to the retention of urine by the cast; there was a severe decrease in body weight; as the immobilization is fixed, it is not possible to look at the restricted area frequently to check the possible presence of ulceration or swelling; some rats were able to slip out of the immobilization. Similar difficulties were also described in previous stud- 

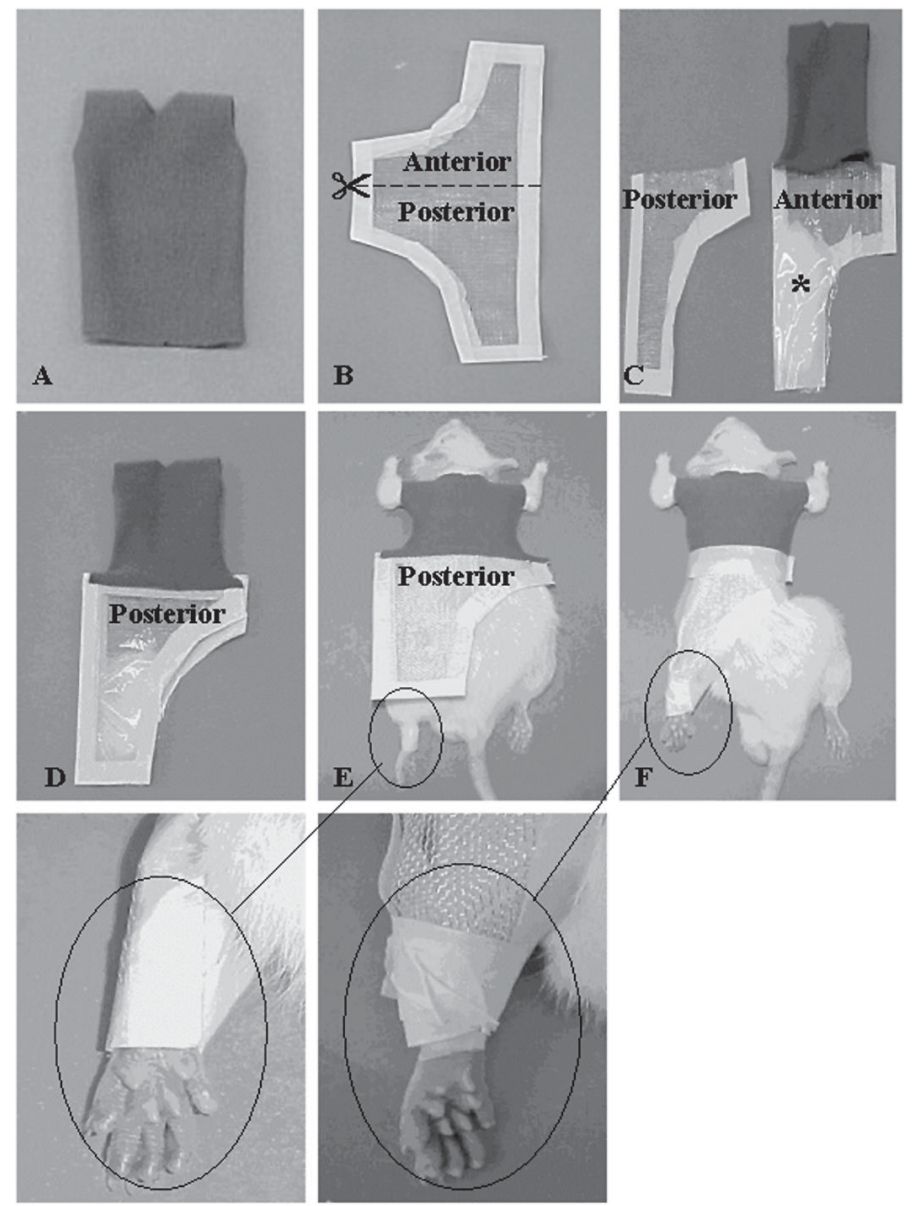

Figure 1. Sequence of hind limb immobilization. $A$, The upper part is similar to a T-shirt made of cotton. $B$, The lower part, made of steel mesh, has its borders protected with adhesive tape and is then divided into two parts (anterior and posterior). $C$, Next, the two parts are stapled to the anterior and posterior parts of the T-shirt, respectively. To protect the anterior region of the leg, a cotton pad was fixed on the anterior part of the immobilization (asterisk). D, The device is ready to be applied to the rat. $E$, After the rat is dressed with the T-shirt, the left ankle joint is immobilized in full plantar flexion with tape. F, Finally, both the anterior and posterior parts are fitted around the body of the rat and fixed with tape. The detail shows the final shape of the immobilization on the ankle joint.

Figure 2. The mold for hind limb immobilization for rats weighing $291 \pm 35 \mathrm{~g}$. A, Measurements of the upper part (T-shirt), which is made of cotton. $B$, Measurements of the lower part of the mold, made of steel mesh. All the measurements are in $\mathrm{cm}$.

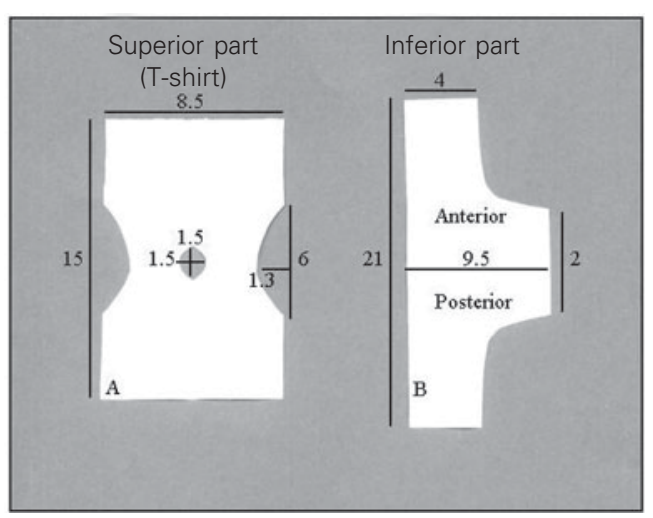

ies using cast immobilization $(1,8)$.

After several tests trying to find an alternative device for immobilization to avoid the problems caused by a cast, we developed the model described here, which permitted later studies of the adaptation of the skeletal muscle of hind limbs submitted to disuse in shortened and stretched positions.

The material used to produce the immobilization device is light ( $12 \mathrm{~g}$ or $4 \%$ of the body weight of the rat) and inexpensive. For each immobilization unit we used $21 \mathrm{~cm}$ of steel mesh (number 6), $15 \mathrm{~cm}$ of cotton cloth, adhesive tape and a stapler (Figures 1 and 2). The device is easily fitted and fixed to the animal. Other advantages are that it is reusable, i.e., the same device can be used several times, and can be rapidly removed from the animals.

Eighteen male albino rats weighing 291 $\pm 35 \mathrm{~g}$ and aged $14 \pm 2$ weeks were used to test this immobilization device. The animals were housed in plastic cages in an animal room under controlled environmental conditions, with free access to standard food and water. The study was conducted in accordance to the Guide for Care and Use of Laboratory Animals (9).

Rats were anesthetized by intraperitoneal injection of xylazine $(12 \mathrm{mg} / \mathrm{kg})$ and ketamine $(95 \mathrm{mg} / \mathrm{kg})$ before the immobilization procedure. The detailed sequence of the immobilization of the left hind limb of the rat is described in Figure 1. Note that the ankle joint is fixed in full plantar flexion, which maintains the soleus and tibialis anterior muscles in the shortened and stretched positions, respectively (Figure 1E,F). The measurements of the upper and lower parts of the immobilization device are also described in Figure 2.

The upper part of the immobilization device is similar to a T-shirt made of cotton cloth (Figure 1A), which permits free movements of the head and forelimbs of the animal (Figure 1E,F).

Before fixing the immobilization device 
to the hind limb, a small cotton pad is placed around the hip and knee joints to prevent possible skin ulceration. Before final immobilization, the ankle (Figure 1) was wrapped with micropore and later fixed in full plantar flexion with adhesive tape (Figure 1E).

Despite the light weight of the immobilization device, the body weight of the animals decreased significantly $(12 \pm 6 \%)$ during 21 consecutive days of immobilization.

The weight of the left soleus muscles, immobilized in the shortened position during the same period of time, was also reduced by $44 \pm 6 \%$ when compared to the contralateral intact soleus $(0.13 \pm 0.04$ vs $0.19 \pm 0.3 \mathrm{~g}$, respectively; $\mathrm{P}=0.002$, paired Student $t$-test). The immobilized soleus lost $19 \pm 7 \%$ of its length $(11.4 \pm 1$ vs $14 \pm 1.5$ $\mathrm{mm}$, respectively; $\mathrm{P}=0.008$, paired Student $t$-test) and $23 \pm 15 \%$ of the number of serial sarcomeres $(5748 \pm 1103$ vs $7517 \pm 797$, respectively; $\mathrm{P}=0.01$, paired Student $t$-test), when compared to the contralateral muscles. The shortened soleus also presented muscle fiber atrophy.

Our data are similar to those reported by different investigators using skeletal muscle immobilization with plaster of Paris and plaster casts. For example, Tabary et al. (10) found a $40 \%$ decrease in the number of serial sarcomeres in the soleus muscle fibers of cats immobilized with a plaster cast in the shortened position for 4 weeks. Williams and Goldspink $(2,11,12)$ also observed muscle fiber atrophy, a decrease in fiber length and a loss of about $40 \%$ of serial sarcomeres in the soleus muscle of mice immobilized in the shortened position for 4 weeks with a plaster cast or plaster of Paris cast. It is also known that several weeks of immobilization contribute to decreasing both the body weight and the weight of skeletal muscles maintained in the shortened position, as observed for the soleus muscle of rats (13).

In contrast, immobilized and stretched tibialis anterior muscles showed discrete atrophy but no difference in weight when compared to the contralateral muscle $(0.57 \pm$ 0.06 vs $0.56 \pm 0.09 \mathrm{~g} ; \mathrm{P}=0.6$, paired Student $t$-test). This result is also similar to data reported in previous studies in which tibialis anterior muscle was immobilized in the stretched position using a plaster cast (14). Since muscle stretching is due to bone growth it is considered an important stimulus for the normal postnatal increase in the serial sarcomere number. Several studies carried out on animal models reported that skeletal muscles of mammals immobilized with a plaster cast or plaster of Paris cast in a maximal stretch position increase muscle protein synthesis and the number of serial sarcomeres (for a review, see Ref. 14).

No skin ulceration or foot swelling was found in the animals when the immobilization was removed.

The immobilization device proposed here was effective in producing chronic muscle disuse in the hind limbs of rats and is a good alternative to the traditional methods of immobilization.

\section{References}

1. Booth FW \& Kelso JR (1973). Production of rat muscle atrophy by cast fixation. Journal of Applied Physiology, 34: 404406.

2. Williams PE \& Goldspink G (1984). Connective tissue changes in immobilised muscle. Journal of Anatomy, 138: 343350.

3. Williams PE, Catanese $T$, Lucey EG \&
Goldspink G (1988). The importance of stretch and contractile activity in the prevention of connective tissue accumulation in muscle. Journal of Anatomy, 158: 109-114.

4. Williams PE (1988). Effect of intermittent stretch on immobilised muscle. Annals of the Rheumatic Diseases, 47: 1014-1016.

5. Zemková H, Teisinger J, Almon RR,
Vejsada R, Hník P \& Vyskocil F (1990). Immobilization atrophy and membrane properties in rat skeletal muscle fibres. Pflügers Archives, 416: 126-129

6. Karpakka J, Väänänen K, Orava S \& Takala TES (1990). The effects of preimmobilization training and immobilization on collagen synthesis in rat skeletal muscle. International Journal of Sports Medicine, 
11: $484-488$

7. Jarvinen M (1977). Immobilization effect on the tensile properties of striated muscle: an experimental study in the rat. Archives of Physical Medicine and Rehabilitation, 58: 123-127.

8. Kasper CE, McNulty AL, Otto AJ \& Thomas DP (1993). Alterations in skeletal muscle related to impaired physical mobility: an empirical model. Research in Nursing and Health, 16: 265-273.

9. National Research Council (1996). Guide for the Care and Use of Laboratory Animals. National Academy Press, Washing- ton, DC, USA.

10. Tabary JC, Tabary C, Tardieu C, Tardieu G \& Goldspink G (1972). Physiological and structural changes in the cat soleus muscle due to immobilization at different lengths by plaster casts. Journal of Physiology, 224: 231-244.

11. Williams PE \& Goldspink G (1973). The effect of immobilization on the longitudinal growth of striated muscle fibres. Journal of Anatomy, 116: 45-55.

12. Williams PE \& Goldspink G (1978). Changes in sarcomere length and physiological properties in immobilized muscle.
Journal of Anatomy, 127: 459-468.

13. Zarzhevsky N, Carmeli E, Fuchs D, Coleman R, Stein H \& Reznick AZ (2001). Recovery of muscles of old rats after hind limb immobilisation by external fixation is impaired compared with those of young rats. Experimental Gerontology, 36: 125140

14. Goldspink G (1999). Molecular mechanisms involved in the determination of muscle fibre mass and phenotype. Advances in Exercise and Sports Physiology, 5: 27-39. 